\title{
ANATOMIC STUDY OF THE NERVOUS COMMUNICATION BETWEEN THE MEDIAN AND MUSCULOUCUTANEOUS NERVE
}

\author{
Edie Benedito Caetano $^{1}$, luiz Ângelo Vieira ${ }^{1}$, Cristina Schmitt Cavalheiro ${ }^{2}$, Mauro Razuk Filho ${ }^{2}$, Marco Antonio Pires Almargo ${ }^{2}$, \\ Mauricio Ferreira Caetano ${ }^{2}$
}

1. Pontifícia Universidade Católica de São Paulo, Faculdade de Ciências Médicas e da Saúde, Department of Surgery. Sorocaba, SP, Brazil. 2. Pontifícia Universidade Católica de São Paulo, Faculdade de Ciências Médicas e da Saúde, Campus Sorocaba, Sorocaba, SP, Brazil.

\section{ABSTRACT}

Objective: The aim of this study was to analyze the incidence of nerve communication between the musculocutaneous and median nerve. Methods: Anatomical dissection of 40 limbs from 20 fetal cadavers was performed at the Laboratory of Anatomy, Faculdade de Ciências Médicas e da Saúde da Pontifícia Universidade Católica de São Paulo. Results: A communicating branch was found in 10 upper limbs. In nine limbs there was a musculocuta- neous-median anastomosis (type I); and in one limb there was a median-musculocutaneous anastomosis (type II). Conclusion: It is very important to know these anatomical variations, especially when considering clinical examination, diagnostic, prognostic and surgical treatment. Level of Evidence IV, Case Series.

Keywords: Musculocutaneous nerve. Median nerve. Anastomosis, surgical/methods. Nerve transfer. Ulnar nerve.

Citation: Caetano EB, Vieira LA, Cavalheiro CS, Razuk Filho M, Almargo MAP, Caetano MF. Anatomic study of the nervous communication between the median and musculoucutaneous nerve. Acta Ortop Bras. [online]. 2016;24(4):200-3. Available from URL: http://www.scielo.br/aob.

\section{INTRODUCTION}

From the brachial plexus toward the hand, we can find anomalous nerve branches, which can form anastomoses in peculiar places that have clinical and functional relevance. The nerve communication (anatomical variations) between the median and ulnar nerve in the forearm (Martin Gruber anastomosis), ${ }^{1}$ between the thenar motor branch of the median nerve and the deep branch of the ulnar nerve in the palm of the hand (Cannieu and Riché anastomosis) ${ }^{2}$ have been described. Moreover, even between the sensory branches of both nerves in the hand palm (Berretini anastomosis) ${ }^{3}$ or superficial sensory communicating branch have been described with a certain frequency in the literature and has been the object of our studies.

These anatomical variations (nerve anastomoses) generate the transfer of fascicles between the nerves, causing change from the normal anatomical pattern of motor and sensory innervation. The literature shows that the incidence of nerve communication is variable when comparing different methods of investigation, namely by electromyography studies, selective anesthetic nerve block or by anatomical dissections. According to Sunderland, ${ }^{4}$ there are several factors that make it difficult to assess nerve function, the main factors are anatomic variations, or also the failure to evaluate the role of deceptive movements, because they allow imitate and cover up the loss of the original movements. If these factors are not valued, errors in diagnosis and evaluation of results will be inevitable. The objective of this study is to demonstrate through anatomical dissections in the arms of fetuses, the presence of anastomoses (nerve communication) between the musculocutaneous and median nerves (MCN-MN).

The musculocutaneous nerve and the lateral root of the median nerve originate from the lateral cord of the brachial plexus. It is possible that in embryonic development some nerve fascicles that originally were part of the median nerve were transferred to the musculocutaneous nerve, and through these nerve communications in the arms, these fascicles are recovered by the median nerve. ${ }^{5,6}$

\section{MATERIALS AND METHODS}

We dissected 40 arms of 20 fetuses' bodies (stillborn) from the Anatomy Laboratory of Faculdade de Ciências Médicas e da Saúde da Pontifícia Universidade Católica de São Paulo, Campus Sorocaba. Regarding gender, 13 corpses were male and seven female. Limbs deformed by trauma, malformations and scars were excluded.

A straight incision was made in the anterior compartment of the arm following the anterior midline, beginning in the supraclavicular region and ending in the cubital fossa. Two flaps including the skin and subcutaneous tissue were folded to the medial and lateral sides, respectively. The same was done in relation to the arm fascia, thereby exposing the whole musculature. Tenotomy of the major and minor pectoral muscles was performed, and the clavicle was removed for better exposure of the entire brachial plexus. Thus, it was possible to identify the medial and lateral fascicles.

All the authors declare that there is no potential conflict of interest referring to this article. 
Dissection was done from proximal to distal, following the median and musculocutaneous nerve, certifying the presence or absence of nerve communication. The arm length was measured from the acromion to the medial epicondyle of the humerus. The length of the anastomotic branch, as well as its location on the arm was also recorded. We used a surgical magnifying glass with an increase of $2.5 \times 350 \mathrm{~mm}$ (Keeler brand) and a delicate surgical instrument box for dissection. At the end, all our dissections were photographically cataloged. This study was approved by the Ethics Committee of Faculdade de Ciências Médicas e da Saúde da Pontifícia Universidade Católica de São Paulo, Campus Sorocaba (PUCSP).

\section{RESULTS}

We dissected 40 arms from 20 fetuses and found 10 anastomoses between the median and musculocutaneous nerve, 9 anastomoses from the musculocutaneous nerve to the median nerve (90\%) and one from the median nerve to the musculocutaneous nerve (10\%). Therefore, in percentage figures we have: $25 \%$ of anastomosis between the median and musculocutaneous nerve and $75 \%$ of anastomosis absence.

Among the 10 anastomoses, we have: 6 anastomoses in the left arm (60\%) and four anastomoses in the right arm (40\%). We recorded bilateralism in just one corpse. The length of the arm measured from the acromion to the medial epicondyle of the humerus ranged between 9 and averaging $10.5 \mathrm{~cm}$, averaging $10 \mathrm{~cm}$. The length of the anastomotic branch ranged from 0.2 to $1.3 \mathrm{~cm}$, with a mean of $0.60 \mathrm{~cm}$. The nerve communication occurred in the upper third of the arm in seven limbs and the third medium in three arms (Figures 1 to 6).

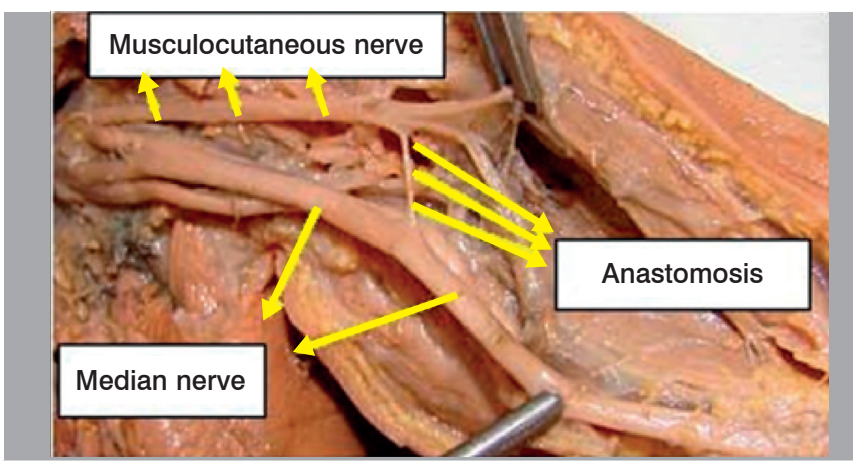

Figure 1. Specimen 8 - Left (presence of musculocutaneous-median anastomotic branch).

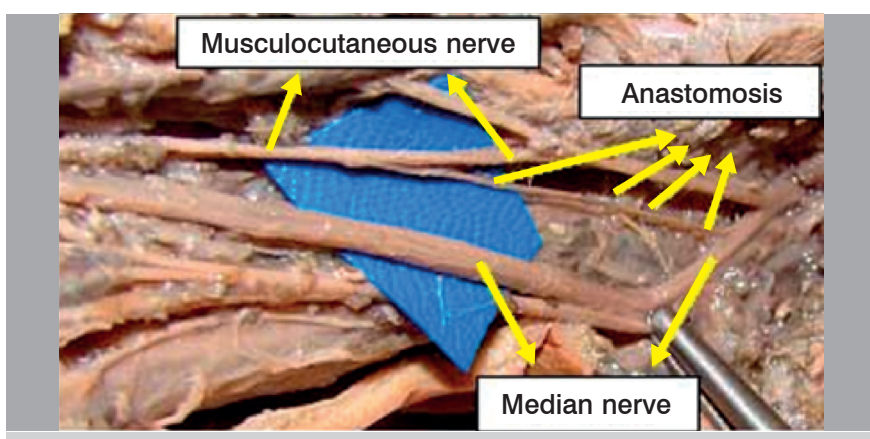

Figure 2. Specimen 12 - Right (presence of median-musculocutaneous anastomotic branch).

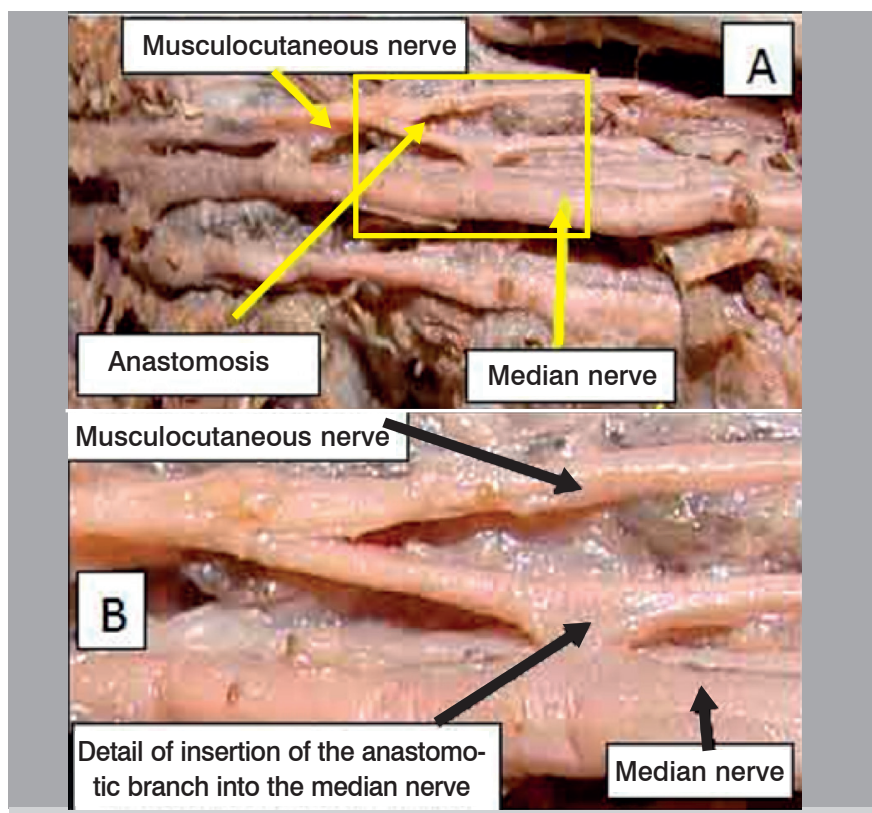

Figure 3. A. Specimen 16 - Left (presence of anastomotic branch); B. Detail of insertion of the anastomotic branch in the median nerve.

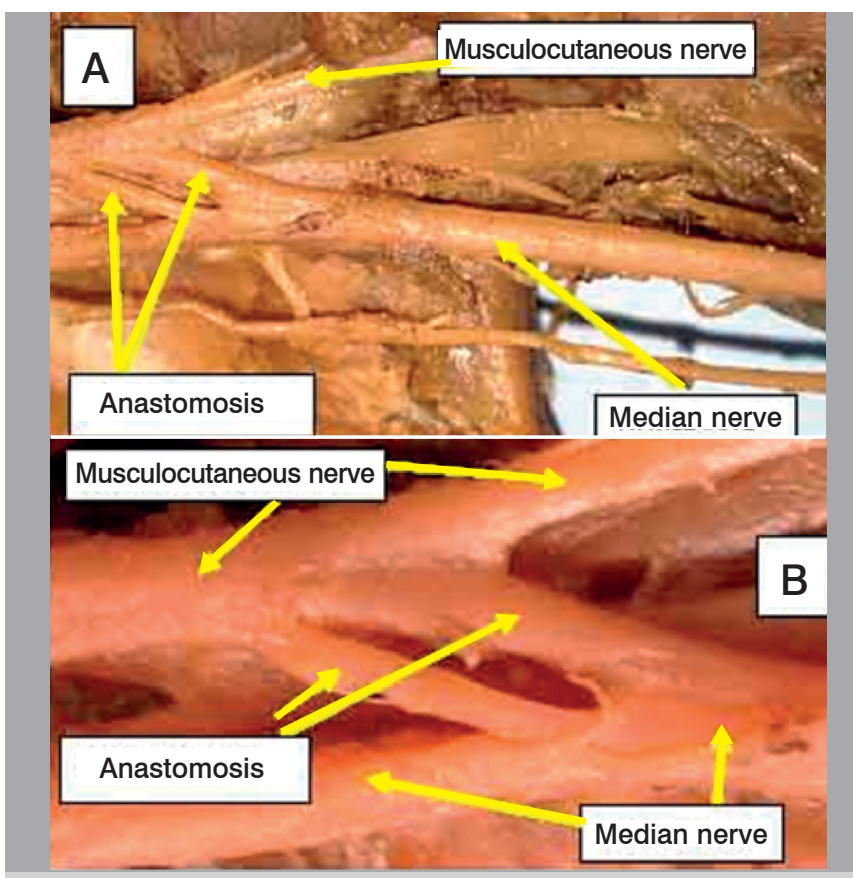

Figure 4. Specimen 26 - A. Left (presence of double anastomotic branch); B. detail of double anastomotic branch.

\section{DISCUSSION}

Some authors ${ }^{7-9}$ reported MCN-MN communication incidence higher than $40 \%$ of cases, others ${ }^{6,10-12}$ less than $15 \%$. We recorded a $25 \%$ incidence in limbs of dissected fetuses. Our results are close to those described by most as authors, ${ }^{5,13-15}$ since we recorded a nerve communication in $25 \%$ of limbs of dissected fetuses. We agree with Ballesteros et al. ${ }^{5}$ that multiple factors such as the sample size, the methodology used and the biological characteristics of the studied population may interfere with the variability of the results. 


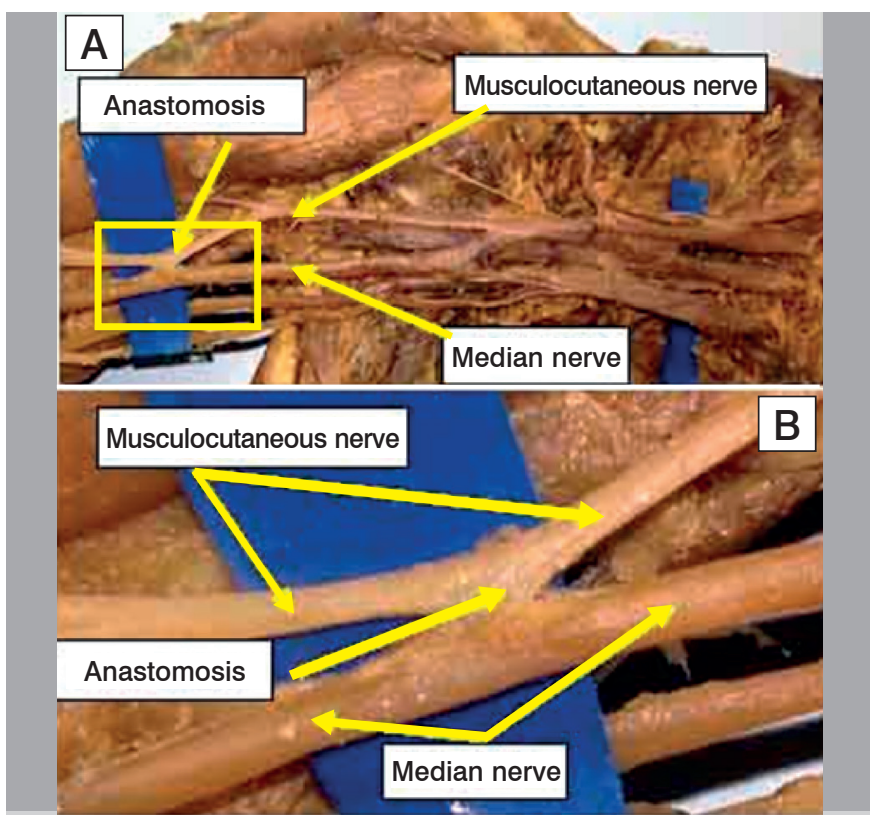

Figure 5. Specimen $16-$ A. Left (presence of anastomotic branch in the middle third of the arm); $\mathrm{B}$. Detail of the insertion of the anastomotic branch into the median nerve.

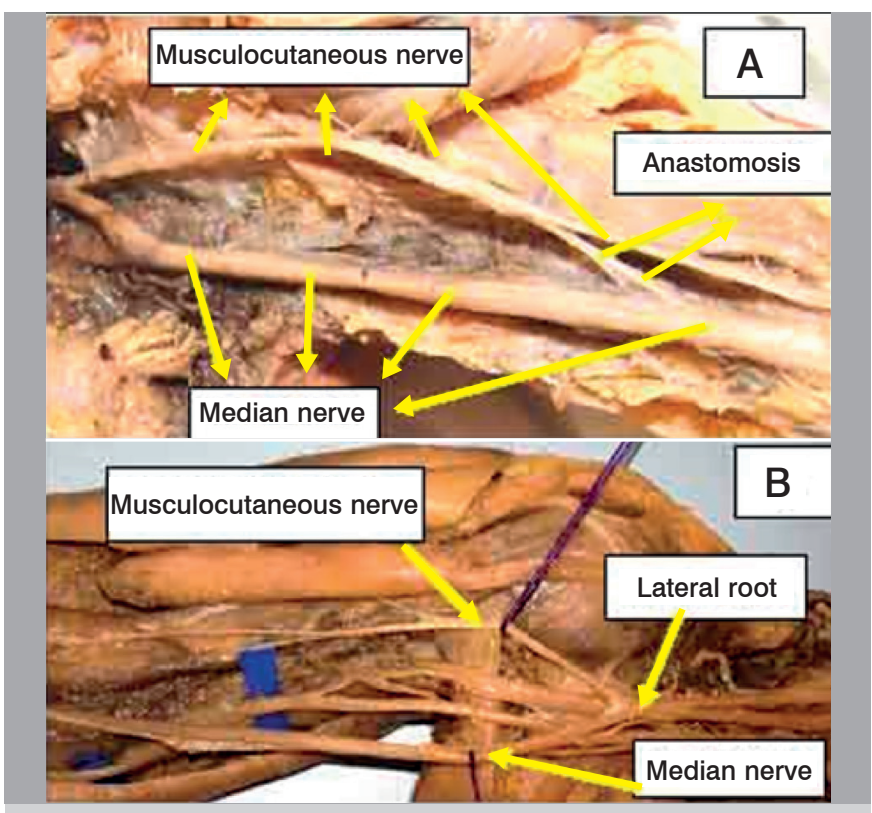

Figure 6. A. Specimen 29 - Left (presence of anastomotic branch in the middle third of the arm); B. Specimen 35 - Right (absence of anastomosis recorded in 30 limbs).

We recorded bilateral occurrence in just one specimen. The low incidence of bilateralism was also recorded by most authors. ${ }^{7,11,16,17}$ (Figure 6) The predominant incidence of only one communicating branch is registered by most studies in the literature. In only one limb we recorded the presence of more than two anastomotic branches. (Figure 4)

Most authors only mention that the communication branch goes from NMC to NM. 6,10,12,16-18 However, NM communication NMC was observed for between $2.8 \%$ to $12.8 \%{ }^{5,8}$ We observed a MCN-MN communications in $90 \%$ of our dissections and in only one limb (10\%) we observed MCN-MN communication.
Regarding the length of this anastomotic branch, Ballesteros et al. ${ }^{5}$ registered a mean of $57.8 \mathrm{~mm}$ and Loukas et al. ${ }^{16} 46 \mathrm{~mm}$, while Elgseder and Goldman ${ }^{14}$ reported $18 \mathrm{~mm}$. We worked with fetuses and recorded an average of $0.60 \mathrm{~mm}$ (the length of nerve communication). Uysal et al. ${ }^{6}$ also conducted studies evaluating the anatomical variations of the musculocutaneous nerve in fetuses, but they did not mention the length of nerve communications. We did not register any combination of $\mathrm{MCN}$ MN communication with an additional brachial biceps head, as recorded by the authors. $5,7,8,19$

Knowledge on the existence of communication between MCN$\mathrm{MN}$ is relevant for clinical practice. It allows assessment and appropriate management of motor disorders of the upper limbs caused by peripheral nerve lesions, and allows proper planning for the surgical approach. The musculocutaneous nerve, after passing under the pectoralis minor muscle goes into a narrow space, limited anteriorly by coracobrachialis muscle, and posteriorly by the upper third of the humerus. It can undergo dynamic compression at this location, causing paresthesia in the anterolateral surface of the forearm. This rare compression occurs in athletes and bodybuilders who have these muscles hypertrophied. The carriers of this compression can refer an inaccurate pain in the anterior face of the arm. If the compression become intense and lasts long, hypotrophy may occur at the anterior surface of the arm muscles (biceps and brachial). The presence of fibrous bands between the biceps and brachial muscles may compress the musculocutaneous nerve. ${ }^{20}$ If the compression occurs proximally to nerve communication, it may cause symptoms similar to carpal tunnel syndrome or even symptoms of less frequent compressive neuropathies such as the pronator teres syndrome or anterior interosseous nerve syndrome, depending on the nature of the fibers contained in nerve communication. Similarly, the musculocutaneous nerve damage proximal to nerve communication can cause muscle weakness of the flexor muscles of the forearm or the muscles of the thenar region with clinical signs that simulate a partial injury of the median nerve. It is essential to differentiate a partial or complete nerve injury. However, the correct identification of these variations is not always easy, because it requires accurate clinical examination and electroneuromyography examination. ${ }^{21}$ Changes recorded in electroneuromyography examination without clinical evidence is not sufficient to indicate a surgical procedure. Careful dissection during surgery can prevent the injury from an anastomotic branch. The detailed clinical examination aided by electromyographic methods can assist in the diagnosis and prevent unnecessary surgical procedures. Surgeons who perform neurotization procedures of the musculocutaneous nerve to restore elbow flexion should be aware of these anatomical variations. ${ }^{22}$

The lateral cutaneous nerve of the forearm is continuation of the musculocutaneous nerve. The forced flexion with the forearm in supination puts in tension the lacertus fibrosus and may compress the nerve, thus, triggering painful and paresthetic symptoms in the anterolateral aspect of forearm. ${ }^{20}$ The patient usually complains of burning pain in the anterolateral aspect of the elbow and forearm. The subject may assume an antalgic attitude with elbow flexion and forearm pronation, because the elbow extension and forearm supination tension the tendon of the biceps brachial muscle and the 
lateral cutaneous nerve of the forearm. Therefore, physical or occupational activity in pronosupination with the elbow in extension may trigger the symptoms.

\section{CONCLUSION}

The knowledge on nerve communication is of great significance, especially when considering the physical examination, diagnosis, prognosis and surgical treatment. If these variations are not valued, mistakes and consequences will be inevitable. The nerve communication between the musculocutaneous and median nerves can cause changes in clinical symptoms, especially in patients with carpal tunnel syndrome, since these variations may exacerbate or alleviate the symptoms causing motor and sensory changes different from the usual pattern.

AUTHORS' CONTRIBUTION: Each author contributed individually and significantly to the development of this study. CSC (00000003-3239-8474)* and MRF (0000-0002-2313-471X)* were the main contributors in drafting the manuscript, bibliographic research and statistical analysis. CSC, MRF, MAP (0000-0002-2210-7752)* and MFC (0000-0003-0994-2128)* performed the dissections and photographs of the corpses. EBC (0000-0003-4572-3854)* and LAV (0000-0003-4406-2492)* reviewed the manuscript, contributed to the intellectual concept and coordination of the study and were responsible for guiding the other participants. All authors contributed to the intellectual concept of the study. ${ }^{\star}$ ORCID (Open Research and Contributor ID).

\section{REFERENCES}

1. Gruber W. Ueber die verbindung des nervus medianus mit dem nervus ulnaris am unterame des menschen um der saugethiere. Arch Physiol. 1870;37(2):501- 22.

2. Caetano EB. Contribuição ao estudo da inervação dos músculos da região tenar e da anastomose de Cannieu e Riché [tese]. Sorocaba, SP: Pontifícia Universidade Católica de São Paulo, Faculdade de Ciências Médicas e da Saúde;1982

3. Vieira LA, Caetano MB, Yoshi PM, Sabongi Neto JJ, Caetano EB. Estudo anatômico da anastomose entre os nervos mediano e ulnar na palma da mão. Rev Bras Ortop. 2002;37(8):336-40.

4. Sunderland S. Nervios perifericos y sus lesiones. $2^{2}$ Ed. Barcelona: Salvat; 1985

5. Ballesteros RE, Forero PL, Buitrago ER. Comunicação entre os nervos musculocutâneo e mediano no braço: estudo anatômico e implicações clínicas. Rev Bras Ortop. 2015;50(5):367-72.

6. Uysal II, Karabulut AK, Büyükmumcu M, Unver Dogan N, Salbacak A. The course and variations of the branches of the musculocutaneous nerve in human fetuses. Clin Anat. 2009;22(3):337-45.

7. Kosugi K, Shibata S, Yamashita H. Supernumerary head of biceps brachii and branching pattern of the musculocutaneus nerve in Japanese. Surg Radiol Anat. 1992;14(2):175-85.

8. Maeda S, Kawai K, Koizumi M, Ide J, Tokiyoshi A, Mizuta H, et al. Morphological study of the communication between the musculocutaneous and median nerves. Anat Sci Int. 2009;84(1-2):34-40.

9. Guerri-Guttenberg RA, Ingolotti M. Classifying musculocutaneous nerve variations. Clin Anat. 2009;22(6):671-83.

10. Bhattarai C, Poudel PP. Unusual variation in musculocutaneous nerves in Nepalese. Kathmandu Univ Med J (KUMJ). 2009;7(28):408-10.

11. Choi D, Rodríguez-Niedenführ M, Vázquez T, Parkin I, Sañudo JR. Patterns of

Acta Ortop Bras. 2016;24(4):200-3 connections between the musculocutaneous and median nerves in the axilla and arm. Clin Anat. 2002;15(1):11-7.

12. Beheiry EE. Anatomical variations of the median nerve distribution and communication in the arm. Folia Morphol (Warsz). 2004;63(3):313-8.

13. Holinshead WH, Rosse C. Anatomia. 4a ed. Rio de Janeiro: Interlivros; 1991.

14. Eglseder WA Jr, Goldman M. Anatomic variations of the musculocutaneous nerve in the arm. Am J Orthop (Belle Mead NJ). 1997;26(11):777-80.

15. Kervancioglu $P$, Orhan M, Kilinc N. Patterns of motor branching of the musculocutaneous nerve in human fetuses and clinical significance. Clin Anat. $2011 ; 24(2): 168-78$.

16. Loukas M, Aqueelah $\mathrm{H}$. Musculocutaneous and median nerve connections within, proximal and distal to the coracobrachialis muscle. Folia Morphol (Warsz). 2005;64(2):101-8.

17. Venieratos $D$, Anagnostopoulou S. Classification of communications between the musculocutaneous and median nerves. Clin Anat. 1998;11(5):327-31.

18. Le Minor JM. A rare variation of the median and musculocutaneous nerves in man. Arch Anat Histol Embryol. 1990;73:33-42.

19. Oztürk NC, Uzmansel D, Oztürk H. An unreported pattern of musculocutaneous and median nerve communication with multiple variations of biceps brachii: a case report. Surg Radiol Anat. 2010;32(9):887-90.

20. Cetano EB, Lech O. Síndromes compressivas do membro superior. Rio de Janeiro: Dilivros; 2016.

21. Kimura J, Murphy MJ, Varda ?DJ. Electrophysiological study of anomalous innervation of intrinsic hand muscles. Arch Neurol. 1976;33(12):842-4.

22. Bertelli JA, Ghizoni MF. Lesões reumática do plexo braquial. In: Pardini AG, Freitas A, editores. Traumatismos da mão. 4a ed. Rio de Janeiro: Medbook; 2008. p. 377-410. 